ELECTRONIC LETTER

\title{
Homozygosity for a frequent and weakly penetrant predisposing allele at the RET locus in sporadic Hirschsprung disease
}

\author{
A Pelet, L de Pontual, M Clément-Ziza, R Salomon, C Mugnier, F Matsuda, M Lathrop, A Munnich, \\ J Feingold, S Lyonnet, L Abel, J Amiel
}

J Med Genet 2005;42:e18 (http://www.jmedgenet.com/cgi/content/full/42/3/e18). doi: 10.1136/jmg.2004.028746

$\mathrm{H}$ irschsprung disease (HSCR), the most common malformation of the hindgut ( $1 / 5000$ live births), is a single-field neural crest derived malformation characterised by the absence of enteric ganglia along a variable length of the intestine. ${ }^{1}$ The genetics of HSCR are complex, considering a skewed sex ratio in favour of females (1/4) and recurrence risk figures whose values depend on the length of the aganglionic segment as well as the gender of affected individuals (mean value of $4 \%$, ranging from 1 to $30 \%$ ). ${ }^{2}{ }^{3}$ All genetic and functional evidence points to the RET protooncogene as the major disease causing locus in HSCR. In particular, almost all HSCR families co-segregate with markers of chromosome 10q11.2 where the RET gene locus has been mapped, ${ }^{4-6}$ although modifier genes are involved..$^{78}$ Nonetheless, in most series worldwide, a mutation within the RET gene coding sequence can be detected in only $40 \%$ and $10-20 \%$ of familial and sporadic cases, respectively. ${ }^{9-11}$ These data led to speculation that a frequent hypomorphic allele(s) must exist at the RET locus. To address this question, several groups have used linkage disequilibrium mapping, mostly in case control studies, ${ }^{12-17}$ taking advantage of single nucleotide polymorphisms (SNPs) scattered along the vast genomic domain encompassing the RET locus $(55 \mathrm{~kb}$ ). These studies consistently indicated that a predisposing haplotype is located in the $5^{\prime}$ region of the RET gene, whatever the ethnic background, with some functional data favouring the role of promotor variants. ${ }^{18} 19$ In order to refine the mapping of predisposing allele(s) at the RET locus and to characterise its genetic behaviour, we used a transmission disequilibrium test (TDT) across the RET gene, in a series of HSCR cases divided according to family type (sporadic or multiplex) and the presence/absence of a RET gene mutation. We found strong association between the disease phenotype and SNPs located 5 ' to the RET locus; we also observed highly significant overtransmission of a predisposing SNP haplotype extending over $23 \mathrm{~kb}$ from the promoter region to exon 2 and encompassing the large intron 1. Over-transmission was not significant when considering cases with classical RET gene mutations. Conversely, the majority of sporadic HSCR cases with no RET gene mutation showed homozygosity for a low-penetrance predisposing haplotype, suggesting its major involvement in the commonest form of HSCR and its dosage-sensitive effect on the RET signalling pathway. The variable prevalence of the HSCR predisposing RET haplotype in the general population may account for the ethnic dependant prevalence of the disease.

\section{METHODS}

HSCR families

A total of 81 non-syndromic HSCR families, whose parents were available for study, were included. The series was divided into 66 single cases (46 males and 20 females),

\section{Key points}

- The genetics of Hirschsprung disease (HSCR), the most common malformation of the hindgut, are complex.

- Studies have consistently indicated that a predisposing haplotype is located in the 5' region of the RET gene.

- A transmission disequilibrium test across the RET gene was used in a series of 81 HSCR cases divided according to the presence/absence of a RET gene mutation and family type (sporadic or multiplex).

- A strong association was found between the disease phenotype and single nucleotide polymorphisms (SNPs) located 5' to the RET locus. Highly significant over-transmission of a predisposing SNP haplotype was also observed, extending over $23 \mathrm{~kb}$ from the promoter region to exon 2 and encompassing the large intron 1.

- Most sporadic HSCR cases with no RET gene mutation showed homozygosity for a low-penetrance predisposing haplotype, opposite to HSCR cases harbouring a RET gene mutation.

denoted as sporadic, and 15 one-generation families with at least two affected sibs (a total of 31 affected individuals including 18 males and 13 females), denoted as multiplex. Altogether, short segment and long segment HSCR was found in 45 and 29 cases, respectively, while the length of the aganglionic segment was not known in 23 cases.

\section{RET mutation screening}

Blood samples were obtained with informed consent and DNA was extracted according to standard protocols. Probands were sequenced for the coding regions of the RET gene (list of primers is available on request). When a RET gene mutation was identified in the proband, all family members were sequenced for the appropriate exon in order to define their molecular status regarding the mutation.

\section{SNP genotyping}

All affected individuals and their parents were also sequenced for regions containing known polymorphisms. We subsequently focused on four SNPs encompassing the $5^{\prime}$ region of the RET locus from the proximal promotor at -5 (SNP-5, G/A, rs 109000296) and -1 (SNP-1, C/A,

Abbreviations: $95 \% \mathrm{Cl}, 95 \%$ confidence interval; $\mathrm{HSCR}$, Hirschsprung disease; IBDI, one allele identical by descent; OR, odds ratio; SNP, single nucleotide polymorphism; TDT, transmission disequilibrium test 
Table 1 Transmission disequilibrium of RET 5' SNPs in non-mutated HSCR families

\begin{tabular}{|c|c|c|c|c|c|c|}
\hline & SNP & $\begin{array}{l}\text { Predisposing } \\
\text { allele (PA) }\end{array}$ & $\begin{array}{l}\text { Frequency } \\
\text { of PA }\end{array}$ & $\begin{array}{l}\text { Informative } \\
\text { families (n) }\end{array}$ & p Value & OR $(95 \% \mathrm{Cl})$ \\
\hline \multirow[t]{4}{*}{ Total $(n=66)$} & -5 & $A$ & 0.45 & 46 & $<10^{-6}$ & $8.3(4.0$ to 17.2$)$ \\
\hline & -1 & C & 0.71 & 32 & $2.0^{-5}$ & 4.6 (2.3 to 9.5$)$ \\
\hline & IVSI & $\mathrm{T}$ & 0.45 & 46 & $<10^{-6}$ & 7.5 (3.7 to 14.8 ) \\
\hline & Exon 2 & $A$ & 0.45 & 36 & $10^{-6}$ & $5.7(2.9$ to 11.1$)$ \\
\hline \multirow[t]{4}{*}{ Sporadic cases $(n=57)$} & -5 & $A$ & 0.45 & 40 & $<10^{-6}$ & 18.0 (5.6 to 57.5$]$ \\
\hline & -1 & $\mathrm{C}$ & 0.71 & 27 & 0.0002 & $5.8(2.2$ to 14.9$)$ \\
\hline & IVSI & $\mathrm{T}$ & 0.45 & 40 & $<10^{-6}$ & 13.7 (4.9 to 37.1$)$ \\
\hline & Exon 2 & $A$ & 0.45 & 29 & 4. $10^{-6}$ & 7.4 (3.1 to 17.2$)$ \\
\hline \multirow[t]{4}{*}{ Multiplex families $(n=9)$} & -5 & A & 0.47 & 6 & 0.12 & $2.4(0.8$ to 6.8$)$ \\
\hline & -1 & $\mathrm{C}$ & 0.69 & 5 & 0.03 & $3.7(1.1$ to 9.9$)$ \\
\hline & IVSI & $\mathrm{T}$ & 0.47 & 6 & 0.10 & $3.4(0.9$ to 7.2$)$ \\
\hline & Exon 2 & $A$ & 0.47 & 7 & 0.08 & $4.2(1.0$ to 9.8$)$ \\
\hline
\end{tabular}

OR, odds ratio; $95 \% \mathrm{Cl}, 95 \%$ confidence interval.

rs109000297), over intron 1 (SNP IVS1, C/T, rs2435357) to exon 2 (G/A, SNP exon 2, rs1800858). All SNPs showed a variant allele with a frequency of at least $25 \%$ (table 1 ) and were tested for Hardy-Weinberg equilibrium.

\section{Statistical methods}

The role of common RET polymorphisms in susceptibility to HSCR was investigated with a family based association study, which avoids possible confounding of gene-phenotype associations due to inappropriately chosen controls or population substructures. We used the $\mathrm{TDT}^{20}$ to search for a distortion of the transmission of alleles from parents to affected offspring. Data were mainly analysed by the family based method implemented in the FBAT haplotype program. ${ }^{21}$ This method allows the use of an empirical variancecovariance estimator, which is consistent when sibling marker genotypes are correlated (for example, when the analysis includes multiplex families), and provides valid significance levels for tests of association. ${ }^{22}$ Data were also analysed by means of conditional logistic regression as described by Schaid and Rowland ${ }^{23}$. This analysis allowed estimation of odds ratios (ORs) and testing for homogeneity of the regression coefficients associated with RET polymorphisms according to some binary criteria such as gender of affected child, gender of transmitting parent, or family type (sporadic/multiplex). All analyses were performed under an additive model, and ORs correspond to the odds of presenting HSCR for 1-2 children versus 2-2 children, or for 1-1 children versus $1-2$ children, in which 1 stands for the predisposing allele and 2 for the protective allele. To test for heterogeneity of the sample according to a binary criterion (for example, sporadic/multiplex families), the analysis was performed on the whole sample (for example, 66 families with no RET gene mutation) and separately on the two subsamples ( 57 sporadic and nine multiplex families). According to the hypothesis of homogeneity, twice the difference between the likelihood of the whole sample and the summed likelihoods of the two subsamples is distributed as a $\chi^{2}$ with 1 degree of freedom.

\section{RESULTS}

\section{RET gene mutation detection}

Direct DNA sequencing of the RET coding sequences detected a mutation in $15 / 81$ (18.5\%) HSCR index cases. The mutation detection rate is thus as low as reported in previous studies and as expected according to the hypothesis of a frequent hypomorphic mutation at the RET locus. Along the same lines, the mutation detection rate was dependent on family type with $6 / 15(40 \%)$ and $9 / 66(13.6 \%)$ in familial and sporadic cases, respectively.

In familial cases, mutations co-segregated with the HSCR phenotype and were mostly missense mutations (G93S,
L452P, C620R, M1064T). Of two conservative changes, one has been shown to impair RET function through aberrant splicing (I647I), while the other (P399P) is likely to do so based on prediction programmes. Inherited mutations originated mainly from the mother (4/6 maternal transmissions), in accordance with the lower HSCR penetrance observed in females. In sporadic cases, mutations were either missense (R287M, R330Q, A487T, R873Q, E921K, N1059S) or splicing mutations (IVS-8 -1 G/A, IVS-7 -5 C/T, IVS-10 +1 G/A). Interestingly, 6/9 mutations occurred de novo.

Mutation screening allowed us to further split our sample into two groups: (i) 66 non-mutated families including 57 sporadic cases ( 38 males and 19 females) and nine multiplex families (all families with two affected children) and (ii) 15 mutated families (nine sporadic cases, four families with two affected children, and two families with three affected children).

\section{SNP and haplotype studies}

No SNP marker showed a significant deviation from the Hardy-Weinberg equilibrium. We concentrated statistical analyses on four SNP markers in a region encompassing $23 \mathrm{~kb}$ of the RET genomic domain from the proximal promotor region to exon 2, where the highest association has been reported ${ }^{15-17}$ and confirmed in the present study. No significant association was found in the 15 HSCR families with a RET gene mutation (nine sporadic, six multiplex), although a trend was observed in favour of a predisposing role of the less common variants of the three SNPs -5, IVS1, and exon 2 .

Conversely, in the 66 HSCR families with no RET gene mutation, results were highly significant for the four SNPs (table 1) with ORs up to 8.3 (95\% CI 4.0 to 17.2) for SNP-5 $\left(\mathrm{p}<10^{-6}\right)$. In that sample, homogeneity tests did not show evidence for heterogeneity taking into account neither the gender of the affected child nor the sex of the transmitting parent. However, this test provided evidence for heterogeneity according to family type (sporadic $v$ multiplex; $\mathrm{p}<0.03$ for SNP-5), justifying splitting the sample between non-mutated multiplex and sporadic cases for further analyses.

In the nine non-mutated multiplex HSCR families (table 1), ORs, although greater than 1, were only suggestive of the role of the four SNPs, probably due, at least in part, to the small number of informative families. In contrast, the analysis of SNP transmission in the 57 non-mutated sporadic cases showed a striking over transmission of the rarer alleles of SNP-5, SNP IVS1, and SNP exon 2 with ORs of 18 (5.6-57.5), 13.7 (4.9-37.1), and 7.4 (3.1-17.2), respectively (table 1). A detailed analysis of SNPs -5 and IVS1 showed an overwhelming transmission of the rarer alleles: allele A for SNP-5 and allele T for SNP IVS1, for 54/57 and 55/59 transmissions, respectively (table 2). Moreover, for both these SNPs, each of 


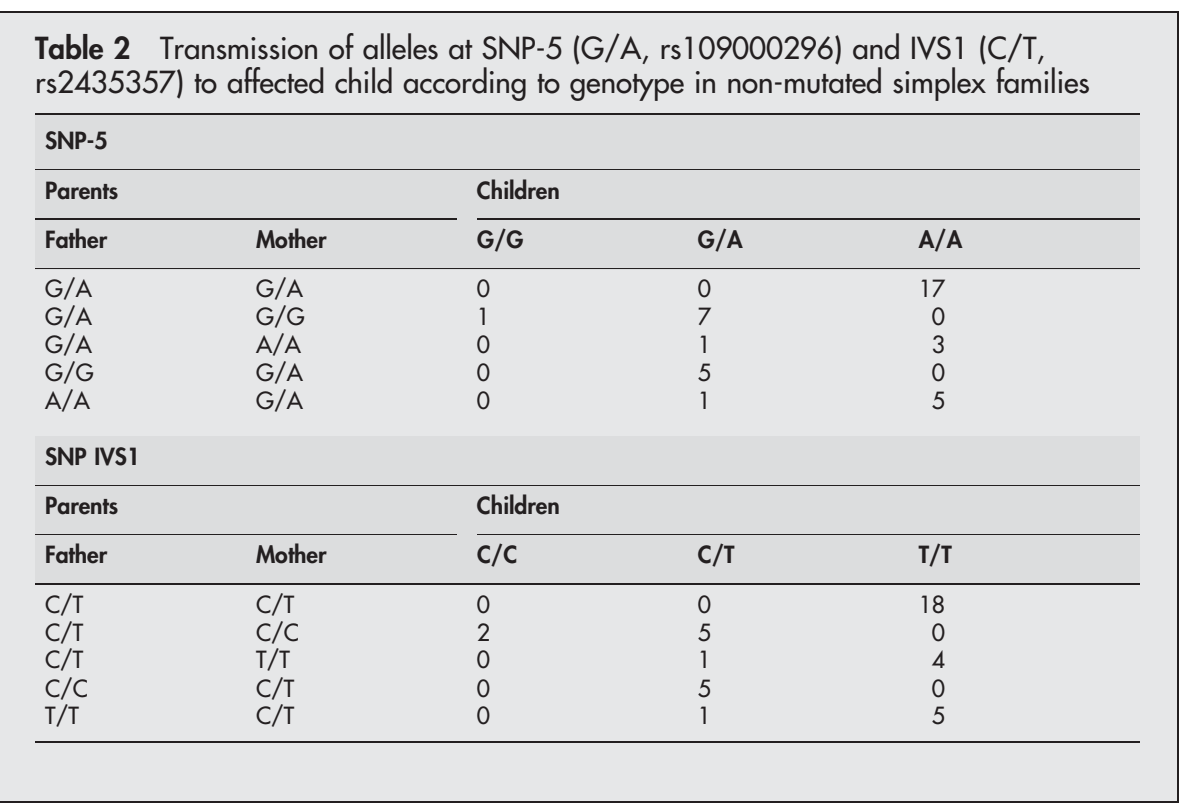

the children born to heterozygous parents was found to be homozygous for the rare allele (17/17 and 18/18 cases for SNP-5 and SNP IVS1). Accordingly, in contrast with other HSCR sub-groups, no difference could be established between paternal and maternal transmission in this series of 57 non-mutated sporadic cases (table 2).

Based on single-loci SNP genotyping, we studied the most frequent haplotypes composed of the highest associated marker loci (table 3). The three SNPs -5, IVS1, and exon 2 are in very strong linkage disequilibrium and have similar allele frequencies, so that they define only two main haplotypes, A-T-A and G-C-G. SNP-1 has a different frequency from the three other SNPs and association with common allele $\mathrm{C}$ of this SNP is very likely due to linkage disequilibrium (allele $\mathrm{C}$ is almost always with the predisposing A-T-A haplotype, but due to higher frequency it is also sometimes with the G-C-G haplotype explaining the lower association of SNP-1 with HSCR). When focusing on the three SNPs with similar frequencies, the A-T-A haplotype of rarer alleles conferred a very high predisposition to HSCR in non-mutated sporadic cases $\left(p=9 \cdot 10^{-6}\right)$. The main effect was due to SNP-5 and SNP IVSI, since the analysis of haplotypes divergent for SNP exon 2 (table 3, upper rows) clearly showed that the A-T haplotype, extending over $10 \mathrm{~kb}$ from the promotor to midintron l, was highly predisposing by itself. However, the analysis of haplotypes composed only of the two SNPs -5 and IVS I did not allow any conclusions to be drawn about a predominant role of either one of these two SNPs (table 3, bottom rows).

\section{DISCUSSION}

As expected in a condition with a complex pattern of inheritance, genetic variations at the major locus RET in HSCR may be of low penetrance, are frequent in the general population, and may lie in non-coding sequences, all features opposite to what is observed for mutations in pure Mendelian traits. This would explain why screening in the RET coding sequences failed to demonstrate mutations in more than 15$20 \%$ of sporadic cases. In order to refine the mapping of such alleles and characterise their genetic behaviour, we investigated a series of 81 HSCR families using TDT across the vast 5' genomic domain of the RET locus, from the promotor to exon 2. Our data agree with the hypothesis of a frequent hypomorphic mutation of the RET gene, with the greatest impact in the subgroup of patients with no RET gene mutation identified within the coding sequence $\left(\mathrm{p}<10^{-6}\right)$. Haplotype studies suggest that this allele is more likely to map $5^{\prime}$ to exon 2 of the RET gene, from the proximal promotor to mid-intron 1.

The vast majority of informative sporadic HSCR cases were found to be homozygous for the predisposing RET gene 5' haplotype. It is worth remembering that segregation metaanalysis in short segment HSCR, the most represented form in sporadic cases $(80 \%)$, showed that the best fit were either the autosomal recessive or the multifactorial models. ${ }^{2}$ We thus propose that the frequent hypomorphic RET allele, located in the $5^{\prime}$ region, results in a dosage-sensitive impairment of the RET signalling pathway, and that homozygosity for that variant is the molecular basis for HSCR in most patients with no coding sequence mutation. Accordingly, the higher penetrance of severe RET gene mutations might explain their higher prevalence in multiplex HSCR families.

The genome-wide scan performed in HSCR sib pairs showed a parent of origin effect at, and only at, the RET

Table 3 Haplotype analysis in the 57 non-mutated HSCR sporadic cases

\begin{tabular}{cccc}
\hline Haplotypes & Frequency & $\begin{array}{c}\text { Informative } \\
\text { families (n) }\end{array}$ & p Value \\
\hline $\begin{array}{c}\text { Predisposing } \\
\text { A-T-A }\end{array}$ & 0.36 & 28 & $9.10^{-6}$ \\
A-T-G & 0.04 & 7 & 0.06 \\
$\begin{array}{c}\text { Protective } \\
\text { G-C-G }\end{array}$ & 0.50 & 30 & $10^{-6}$ \\
G-C-A & 0.04 & 7 & 0.01 \\
Predisposing & & & \\
A-T & 0.40 & 34 & $<10^{-6}$ \\
Protective & 0.53 & 35 & $<10^{-6}$ \\
G-C & 0.03 & 4 & 0.31 \\
G-T & 0.03 & 6 & 1 \\
Neutral & & & \\
A-C & & &
\end{tabular}

Because of linkage disequilibrium, only alleles at SNP-5 (G/A), SNP IVS1 $(C / T)$, and SNP exon 2 (G/A) were considered. Top rows: haplotypes for the three SNPs (-5, IVS1, exon 2); bottom rows: haplotypes for SNPs -5 and IVSI only. Significant results for predisposing haplotypes are in bold. 
locus, with a greater number of maternal transmissions than expected in sibs sharing one allele identical by descent (IBDl). ${ }^{8}$ In this series, we observed homozygosity for the A-T-A haplotype among non-mutated sporadic cases. We can hypothesise that over maternal IBDl sharing at the RET locus holds true only among HSCR patients who inherited a classical RET gene mutation as it is more frequently maternal in one-generation familial cases. Conversely, it is striking that a mutation of the coding sequence of the RET gene occurs de novo in over $50 \%$ of sporadic HSCR cases (this series and Attié et $a l^{9}$ ).

Homozygotes for the A-T haplotype at the RET locus are estimated to be $4 \%$ of the general population. Homozygosity for the predisposing A-T haplotype may, therefore, be a necessary (although not sufficient) prerequisite for HSCR to occur in most non-mutated sporadic cases. According to both the $100 \%$ heritability of HSCR and the observations made in our previous sib-pair study, ${ }^{8}$ co-inheritance of frequent autosomal dominant predisposing alleles at modifier genes mapping to chromosome $3 \mathrm{p} 21$ and $19 \mathrm{q} 12$ may be necessary to explain the $1 / 5000$ prevalence of HSCR in Caucasians. Along these lines, it is tempting to speculate that the variable prevalence of HSCR across different ethnic backgrounds may result from the variable frequency of the A-T predisposing haplotype, as suggested by linkage disequilibrium studies at the RET locus. ${ }^{24}$

\section{ACKNOWLEDGEMENTS}

We thank the Association Française de la maladie de Hirschsprung for support and participation in the study.

\section{Authors' affiliations}

A Pelet, L de Pontual, M Clément-Ziza, R Salomon, C Mugnier,

A Munnich, J Feingold, S Lyonnet, J Amiel, Unité de Recherches sur les Handicaps Génétiques de l'Enfant INSERM U-393 and Département de Génétique, Hôpital Necker-Enfants Malades, Paris, France

F Matsuda, M Lathrop, Centre National de Génotypage, Evry, France L Abel, Laboratoire de Génétique Humaine des Maladies Infectieuses, INSERM U-550, Hôpital Necker-Enfants Malades, University Paris 5 Medical School, Paris, France

This work was supported by European Union grants 2001-01646 and grants from GIS Maladies Rares INSERM-AFM.

Competing interests: none declared

Correspondence to: Stanislas Lyonnet, Département de Génétique, Hôpital Necker-Enfants Malades, 149, rue de Sèvres, 75743 Paris Cedex 15, France; lyonnet@necker.fr

\section{REFERENCES}

1 Amiel J, Lyonnet S. Hirschsprung disease, associated syndromes, and genetics: a review. J Med Genet 2001;38:729-39.

2 Badner J, Sieber W, Garver K, Chakravarti A. A genetic study of Hirschsprung disease. Am J Hum Genet 1990;46:568-80.

3 Chakravarti A, Lyonnet S. Hirschsprung disease. In: Scriver CR, Beaudet AL, Sly WS, eds. Metabolic and molecular bases of inherited disease, 8th ed. New York: McGraw-Hill, 2001:6231-56.

4 Lyonnet S, Bolino A, Pelet A, Abel L, Nihoul-Fékété C, Briard ML, Mok Siu V, Kääriäinen $H$, Martucciello $G$, Lerone $M$, Puliti $A$, Lou $Y$, Weissenbach J, Devoto M, Munnich A, Romeo G. A gene for Hirschsprung disease maps to the proximal long arm of chromosome 10. Nat Genet 1993;4:346-50.
5 Edery P, Lyonnet S, Mulligan LM, Pelet A, Dow E, Abel L, Holder S, NihoulFékété C, Ponder BAJ, Munnich A. Mutations of the RET proto-oncogene in Hirschsprung's disease. Nature 1994;367:378-80.

6 Romeo G, Ronchetto P, Yin L, Barone V, Seri M, Ceccherini I, Pasini B, Bocciardi $R$, Lerone $M$, Kääriäinen $H$, Martucciello $G$. Point mutations affecting the tyrosine kinase domain of the RET proto-oncogene in Hirschsprung's disease. Nature 1994;367:377-8.

7 Bolk S, Pelet A, Hofstra RM, Angrist M, Salomon R, Croaker D, Buys CH, Lyonnet S, Chakravarti A. A human model for multigenic inheritance: phenotypic expression in Hirschsprung disease requires both the RET gene and a new 9q31 locus. Proc Natl Acad Sci U S A 2000;97:268-73.

8 Gabriel SB, Salomon R, Pelet A, Angrist M, Amiel J, Fornage M, Attié-Bitach T, Olson JM, Steffann J, Hofstra R, Buys C, Munnich A, Lyonnet S, Chakravarti A. Segregation at three loci explains familial and population risk in Hirschsprung disease. Nat Genet 2002;31:89-93.

9 Attié T, Pelet A, Edery P, Eng C, Mulligan LM, Amiel J, Boutrand L, Beldjord S, Nihoul-Fékété C, Munnich A, Ponder BAJ, Lyonnet S. Diversity of RET protooncogene mutations in familial and sporadic Hirschsprung disease. Hum Mol Genet 1995;4:1381-6.

10 Angrist M, Bolk S, Thiel B, Puffenberger EG, Hofstra RM, Buys CH, Cass DT, Chakravarti A. Mutation analysis of the RET receptor tyrosine kinase in Hirschsprung disease. Hum Mol Genet 1995;4:821-30.

11 Seri M, Yin L, Barone V, Bolino A, Celli I, Bocciardi R, Pasini B, Ceccherini I, Lerone M, Kristoffersson U, Larsson LT, Casasa JM, Cass DT, Abramowicz MJ, Vanderwinden JM, Kravcenkiene I, Baric I, Silengo M, Martucciello G, Romeo G. Frequency of RET mutations in long- and short-segment Hirschsprung disease. Hum Mutat 1997;9:243-9.

12 Borrego S, Saez ME, Ruiz A, Gimm O, Lopez-Alonso M, Antinolo G, Eng C. Specific polymorphisms in the RET proto-oncogene are over-represented in patients with Hirschsprung disease and may represent loci modifying phenotypic expression. J Med Genet 1999;36:771-4

13 Fitze G, Schreiber M, Kuhlisch E, Schackert HK, Roesner D. Association of RET protooncogene codon 45 polymorphism with Hirschsprung disease. Am J Hum Genet 1999;65:1469-73.

14 Borrego S, Ruiz A, Saez ME, Gimm O, Gao X, Lopez-Alonso M, Hernandez A, Wright FA, Antinolo G, Eng C. RET genotypes comprising specific haplotypes of polymorphic variants predispose to isolated Hirschsprung disease. J Med Genet 2000;37:572-8.

15 Griseri P, Pesce B, Patrone G, Osinga J, Puppo F, Sancandi M, Hofstra R, Romeo G, Ravazzolo R, Devoto M, Ceccherini I. A rare haplotype of the RET proto-oncogene is a risk modifying allele in Hirschsprung disease. Am J Hum Genet 2002;71:969-74.

16 Fitze G, Cramer J, Ziegler A, Schierz M, Schreiber M, Kuhlisch E, Roesner D, Schackert HK. Association between c135G/A genotype and RET protooncogene germline mutations and phenotype of Hirschsprung's disease. Lancet 2002;359:1200-5.

17 Borrego S, Wright FA, Fernandez RM, Williams N, Lopez-Alonso M, Davuluri R, Antinolo G, Eng C. A founding locus within the RET protooncogene may account for a large proportion of apparently sporadic Hirschsprung disease and a subset of cases of sporadic medullary thyroid carcinoma. Am J Hum Genet 2003;72:88-100.

18 Fitze G, Appelt H, Konig IR, Gorgens H, Stein U, Walther W, Gossen M, Schreiber M, Ziegler A, Roesner D, Schackert HK. Functional haplotypes of the RET proto-oncogene promoter are associated with Hirschsprung disease (HSCR). Hum Mol Genet 2003;12:3207-14.

19 Sancandi M, Griseri P, Pesce B, Patrone G, Puppo F, Lerone M, Martucciello G, Romeo G, Ravazzolo R, Devoto M, Ceccherini I. Single nucleotide polymorphic alleles in the $5^{\prime}$ region of the RET proto-oncogene define a risk haplotype in Hirschsprung's disease. J Med Genet 2003:40:714-8.

20 Spielman RS, McGinnis RE, Ewens WJ. Transmission test for linkage disequilibrium: the insulin gene region and insulin-dependent diabetes mellitus (IDDM). Am J Hum Genet 1993;52:506-16.

21 Horvath S, Xu X, Lake SL, Silverman EK, Weiss ST, Laird NM. Family-based tests for associating haplotypes with general phenotype data: application to asthma genetics. Genet Epidemiol 2004;26:61-9.

22 Lake SL, Blacker D, Laird NM. Family-based tests of association in the presence of linkage. Am J Hum Genet 2000;67:1515-25.

23 Schaid DJ, Rowland C. Use of parents, sibs, and unrelated controls for detection of associations between genetic markers and disease. Am J Hum Genet 1998;63:1492-506.

24 Chattopadhyay P, Pakstis AJ, Mukherjee N, lyengar S, Odunsi A, Okonofua F, Bonne-Tamir B, Speed W, Kidd JR, Kidd KK. Global survey of haplotype frequencies and linkage disequilibrium at the RET locus. Eur J Hum Genet 2003; 11:760-9. 